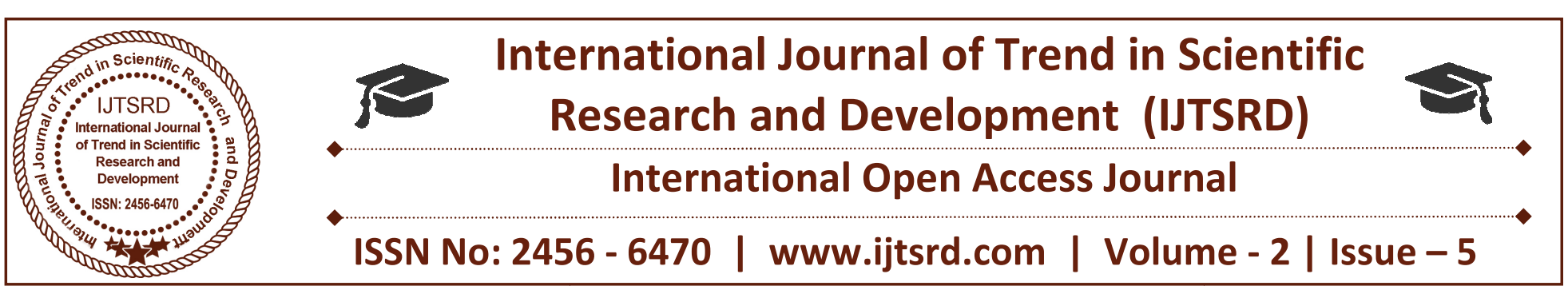

\title{
Comparison of Two Compensation Control Strategies for Shunt Active Power Filter in three Systems
}

\author{
Mr. Amit Kumar Rajan ${ }^{1}$, Dr. E Vijay Kumar ${ }^{2}$ \\ ${ }^{1}$ M.Tech. Scholar, ${ }^{2}$ Head of Electrical \& Electronics Engineering \\ RKDF Institute of Science \& Technology, Sarvepalli Radhakrishnan University, \\ Bhopal, Madhya Pradesh, India
}

\begin{abstract}
Use of nonlinear loads has been increased in large extent in industries now-a-days which injects harmonic currents in supply system. These harmonics creates power quality issue. Shunt Active Power Filter (SAPF) is the popular and efficient solution to reduce these harmonics. SAPF can overcome voltage sag, eliminate harmonics and improves power factor. SAPF reduces total harmonic distortion (THD) to acceptable level. Reference current generation is the heart of APF. Reference current generation using instantaneous reactive power (IRP) theory is presented in this paper. IRP theory is widely used to control active power filters (APFs). Modeling of this technique is implemented in MATLAB/simulink. The system is experimentally implemented using DS1104 card of d SPACE system.
\end{abstract}

Keywords: SAPF, Power quality, IRP Theory, THD, MATLAB/simulinkI

\section{INTRODUCTION}

Power quality issue is becoming very serious now-adays. This is because non linear loads such as electrical machines, static power converters, electric arc furnaces, etc. which mainly lead to harmonic disturbances in power lines. Also power electronic equipments for human comfort plays major role in it. Although these power electronic equipments make our life convenient, it injects lot of harmonic current to the supply system and affects power factor [1]. Conventionally, passive LC filters have been used to eliminate line current harmonics and thereby increase the load power factor. Tuned passive filters are very effective for the elimination of specific harmonic components but has some drawbacks, such as Fixed Compensation, Resonance, huge size
They may cause series and load resonances in the system Also its performance depends on load, it gets affected significantly due to the variation in the filter component values, filter component tolerance, source impedance and frequency of ac source [1]. Shunt Active Power Filter (SAPF) is the effective solution to these problems. Active Filters can be designed to achieve following goals [2]:

Harmonic Compensation

Harmonic Isolation

Reactive power compensation

Voltage regulation

Out of three system based configurations of APF; here we are interested in Shunt Active Power Filter (SAPF).

The Active filters overcome the problem occurring in the passive filter. Major Advantage of Active Filter over Passive Filter is that it can be controlled to compensate harmonics such that Total Harmonic Distortion (THD) lower than 5\% at the PCC can effectively be achieved. SAPF is shown in fig 1 . The reference current generation is like heart for APF.

In this paper reference current generation using IRP theory is presented. The experimental setup is done using DS1104 card of DSPACE system. Finally simulation and experimental results are presented.

\section{CONTROL STRATEGY}

Key factor for successful implementation of SAPF is strategy Control s. Block diagram of control strategy is shown in figure 2 below. In this paper SAPF is controlled using instantaneous reactive power theory (IRP) or $\mathrm{p}-\mathrm{q}$ theory. Using IRP theory, reference 
current will be generated. These reference currents will be further used to generate gate pulses for inverter. The basic principle of reference current generation is shown

\section{EXPERIMENTAL PROTOTYPE}

The real time SAPF controller consist of dSPACE DS1104 interfacing card, current and voltage sensors, inverter consisting IGBTs as switches and a host computer system. The interfacing kit is fixed in host computer system. The experimental setup is as shown in figure below in figure 4 ,

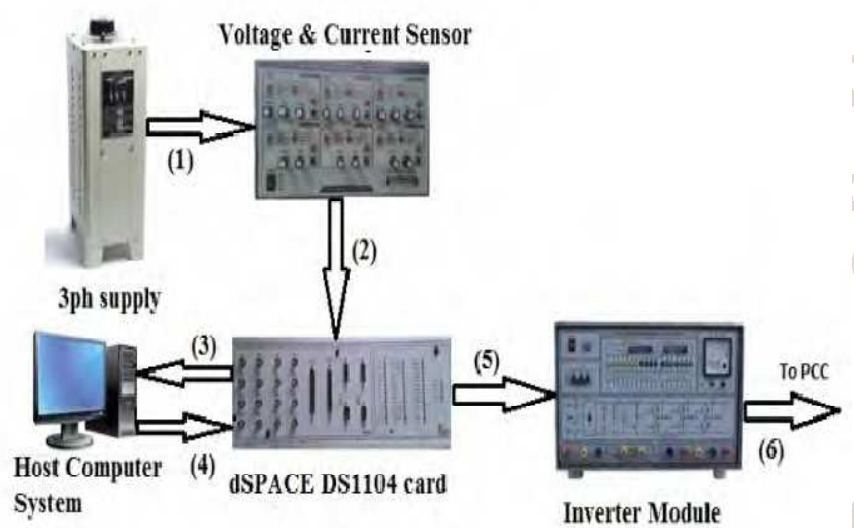

Figure1. Experimental setup

All the components of experimental are shown in figure 4. Numbers in figure shows sequence of flow of signals. As shown in figure, 3-phase supply is given to Hall Effect voltage and current sensors. Voltage and current sensor will convert three phase supply to voltage signals suitable to dSPACE system ( 0 to $\pm 10 \mathrm{~V}$ ). Further these converetd signals are given to Analog to digital converter (ADC) ports of dSPACE system. After simulation of control technique in host computer system, signals will be given to digital to analog converter (DAC) ports of dSPACE system. Gating pulses are also generated through host computer system and given to inverter module through I/O ports of dSPACE system. After that the whole system is connected to supply system through small coupling inductor.

\section{SIMULATION RESULTS}

The proposed system is simulated in MATLAB/simulink along with the control technique proposed in figure 2 and 3 . The system is simulated in MATLAB/ simulink having phase to phase 400v, and frequency of $50 \mathrm{~Hz}$. along with control technique, non linear load and gate pulse generation. SAPF is connected to supply system through very small coupling inductor. The simulation is performed on three phase balanced non linear load; as a result of this following results are obtained. Following figures $5,6 \& 7$ shows source voltage of phase A, source current before compensation and source current after compensation respectively.

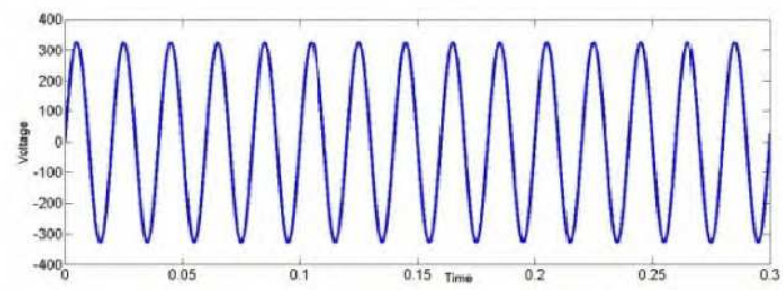

Figure2. Source voltage of phase A

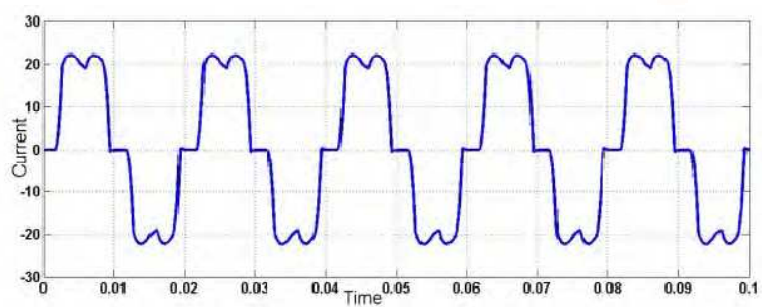

Figure3. Source current before compensation

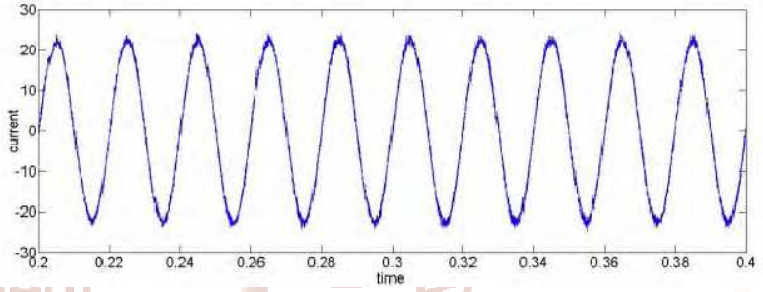

Figure4. Source current after compensation

The load current for phase A is obtained as fallows in figure 5. Also filter current for phase A is obtained as fallows in figures in figure 7

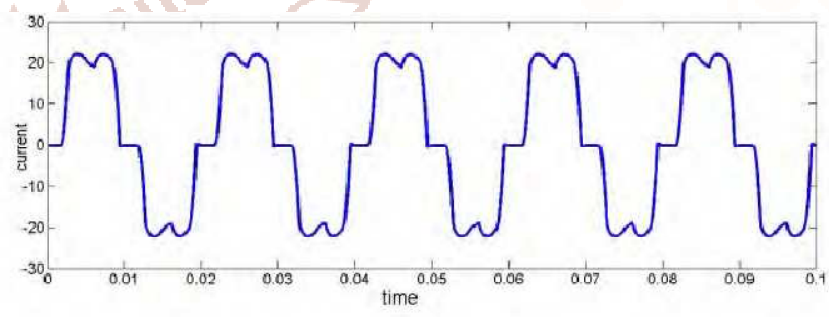

Figure5. Load Current for phase

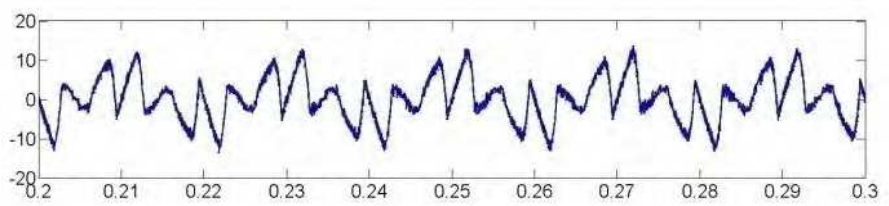

Figure6. Filter current for phase A

THD of the given system shown in figure 11 below, THD is found to be $2.91 \%$ 
International Journal of Trend in Scientific Research and Development (IJTSRD) ISSN: 2456-6470

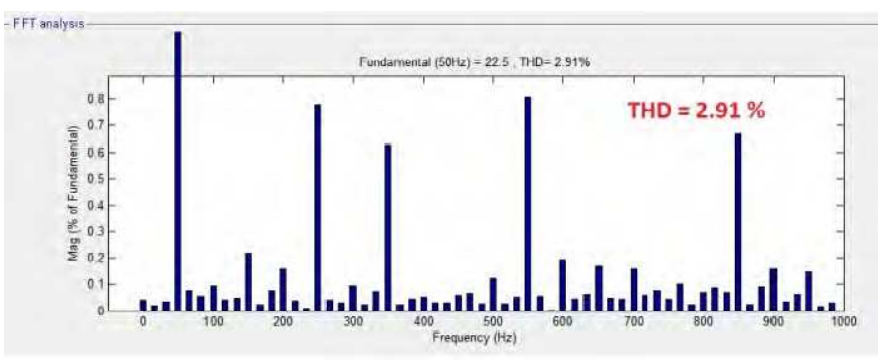

Figure07. THD of system

\section{EXPERIMENTAL RESULTS}

The proposed system is experimentally performed using DS1104 card of dSPACE system. The following results are taken by using FLUKE 43B Power Quality Analyzer,

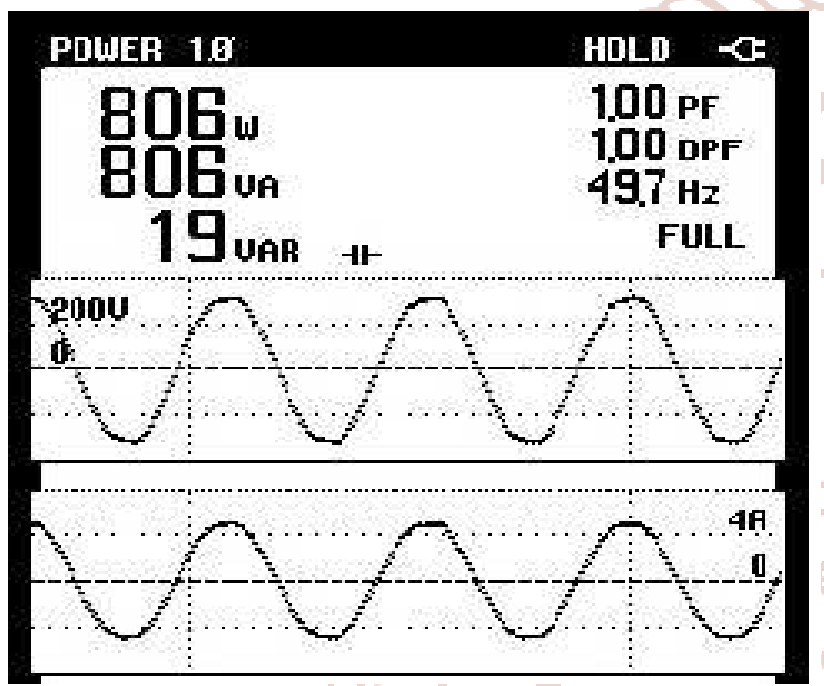

Figure8. Active \& Reactive power of phase A

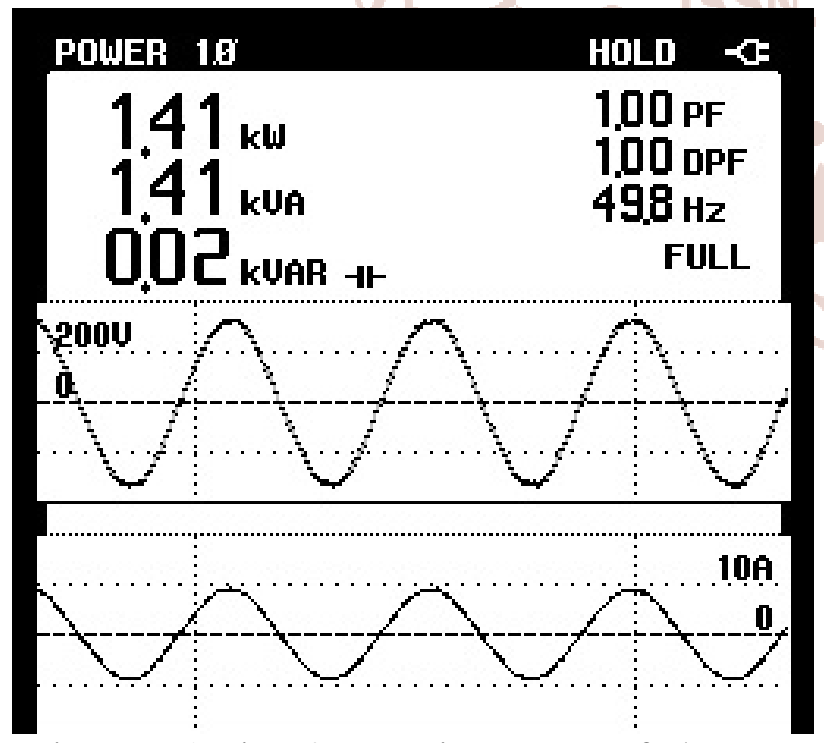

Figure9. Active \& Reactive power of phase B

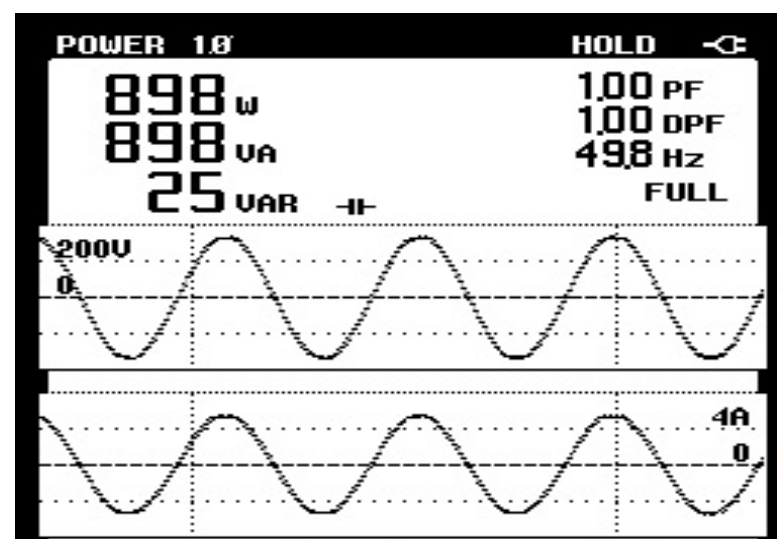

Figure10. Active \& Reactive power of phase c

The sum of all active powers in experimental setup measured by FLUKE meter is found to be $3114 \mathrm{~W}$. This value is verified by using dSPACE DS1104 card is as shown below, and it is found to be $3098 \mathrm{~W}$.

The source voltage and current obtained are as fallows in figure 8. Also figure 10 shows the reference currents generated using $\mathrm{p}-\mathrm{q}$ theory.

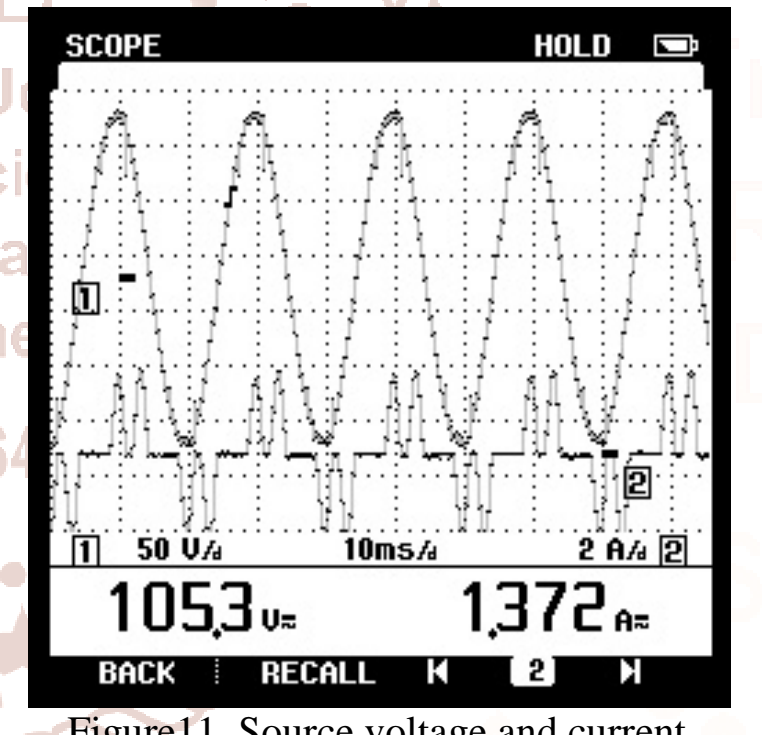

Figure11. Source voltage and current

\section{CONCLUSION}

Reference current is the key factor for successful performance of SAPF. The reference current using instantaneous reactive power theory is presented in this paper. Further these reference currents are used to generate switching pulses for inverter. THD can be maintained to acceptable level using SAPF. The simulation results using MATLAB/simulink verifies that. The system is implemented by using dSPACE DS1104. The experimental results are stated in the paper. The advantages of IRP theory are that it is easy to implement, less mathematical calculations. IRP or p-q theory can effectively and efficiently be used to control shunt active power filters. 


\section{REFERENCES}

1. M. Waware, P. Agarwal, "A Review of multilevel Inverter Based Active Power Filter", International Journal of Computer and Electrical Engineering, Vol. 3, No. 2, April, 2011 1793-8163 196

2. Musa Yusup Lada, Ismadi Bugis, Md Hairul Nizam Talib, "Simulation a Shunt Active Power Filter using MATLAB/Simulink", The 4th International Power Engineering and Optimization Conf. (PEOCO2010), Shah Alam, Selangor, MALAYSIA: 23-24 June 2010

3. María Isabel Milanés Montero, Enrique Romero Cadaval, Fermín Barrero González, "Comparison of Control Strategies for Shunt Active Power Filters in Three-Phase Four-Wire Systems", IEEE transactions on power electronics, vol. 22, no. 1, january 2007

4. Hirofumi Akagi, Hyosung Kim, "The Instantaneous Power Theory on the Rotating p-q-r Reference Frames", IEEE 1999 International Conference on Power Electronics and Drive Systems, PEDS'99, July 1999, Hong Kong

5. Smita Singhai, Bharti Dewani, "Implementation of Active Harmonic Filter with
MATLAB/Simulink to compensate Non-Linear Loads" ,International Journal of Digital Application and Contemporary research, Volume 1, Issue 9, April 2013

6. Maoh-Chin Jiang, "Analysis and Design of a Novel Three-Phase Active Power Filter" , IEEE transactions on aerospace and electronic systems vol. 37, no. 3 july 2001

7. Jaime Prieto, Patricio Salmerón, Reyes S. Herrera, "Practical Design of a Load Compensation Active Conditioner", project by the CICYT (Ministerio de Ciencia y Tecnología, Spain).

8. N. Mendalek, K. AI-Haddad, F. Fnaiech and L. A. Dessaint, "Nonlinear control technique to enhance dynamic performance of a shunt active power filter", IEE Proc-Electr. Power Appl, Vol. 150, No. 4, July 2003.

9. M. Suresh, S. S. Patnaik, Y. Suresh, Prof. A. K. Panda, "Comparison of Two Compensation Control Strategies for Shunt Active Power Filter in Three Phase Four-Wire System" , 978-1-61284220-2/11/ C2011 IEEE 